\title{
Editorial: ONR special issue on multiscale problems of marine composites
}

\author{
Yapa Rajapakse ${ }^{1}$ Young W. Kwon ${ }^{2}$
}

Published online: 26 October 2018

(C) This is a U.S. government work and its text is not subject to copyright protection in the United States; however, its text may be subject to foreign copyright protection 2018

Usage of composite materials has increased gradually for marine structural applications which are subjected to unique environmental conditions such as fluid-structure interactions, moisture and seawater effects, and biofouling.

Two special issues were planned on the topic "Composite Materials and Structures for Marine Applications". The first ONR special issue focused on multiphysics problems of composite structures. Six papers have already been published in the first special issue. The second special issue has six papers on multiscale problems of composites.

The first paper conducted a series of parametric studies using a multiscale model to investigate the effect of low temperature on the carbon fiber composites. The second article studied thermal, thermomechanical, tensile and flexural properties of multi-phase composite including nanoclay and carbon nanotubes. A homogenized structural model was used for the third paper to study bending of multilayered plates containing thin compliant interlayers. The next paper developed a multiscale model which can include various design parameters at different length scales, especially for the viscoelastic behavior of laminated composite beam. The fifth paper presented and discussed the failure criteria for fibrous composite materials and structures in terms of the multiscale approach. The last paper studied polyamide 6 fiber yarns for their moisture effect and creep response because such fiber yarns may be attractive for shallow water mooring line ropes for floating wind turbines.

Publisher's Note Springer Nature remains neutral with regard to jurisdictional claims in published maps and institutional affiliations.

Young W. Kwon

ywkwon2004@yahoo.com

1 Office of Naval Research, Arlington, USA

2 Naval Postgraduate School, 1 University Circle, Monterey, CA 93943, USA 